Anjelane M. Enriquez, MD' Jose M. Carnate Jr., MD²

'Department of Laboratories Philippine General Hospital University of the Philippines Manila

${ }^{2}$ Department of Pathology College of Medicine

University of the Philippines Manila
Correspondence: A/Prof. Dr. Jose M. Carnate Jr. Department of Pathology

College of Medicine, University of the Philippines Manila 547 Pedro Gil St., Ermita 1000 Manila

Philippines

Phone (632) 5264450

Fax (632) 4003638

Email:jmcjpath@yahoo.com

Reprints will not be available from the authors.

The authors have no conflict-of-interest issues to disclose.

The authors declared that this represents original material that is not being considered for publication or has not been published or accepted for publication elsewhere, in full or in part, in print or electronic media; that the manuscript has been read and approved by all the authors, that the requirements for authorship have been met by each author, and that each author believes that the manuscript represents honest work.

Disclosures: The authors signed disclosures that there are no financial or other (including personal) relationships, intellectual passion, political or religious beliefs, and institutional affiliations that might lead to a conflict of interest.

Presented at the Case Report Poster Contest (Second Place), Philippine Society of Pathologists Annual Convention, Dusit Hotel, Makati City, Philippines, April 14, 2011.

\section{Melanotic Neuroectodermal Tumor of Infancy}

\begin{abstract}
A case of melanotic neuroectodermal tumor of infancy (MNETI) is presented. The salient histopathologic features of this unusual neoplasm are discussed including post-chemotherapy morphologic changes.
\end{abstract}

Keywords: Melanotic neuroectodermal tumor of infancy, retinal anlage tumor, progonoma, neuroectodermal tumors

Melanotic Neuroectodermal Tumor of Infancy (MNETI) is a rare neoplasm of early infancy, arising from neural crest cells, with rapid expansile growth and a high recurrence rate. ' Most cases occur in the anterior maxillary alveolus. Prognosis is good for the majority of cases. About 250 cases have been reported in the medical literature. ${ }^{2}$ In the Philippines, there is only one reported case of MNETI since $1983 .{ }^{3}$ In this paper, we describe a case of MNETI in the left maxillary region, as well as its treatment and a literature review in order to discuss different features of this rare pathology.

\section{CASE REPORT}

A four-month-old male infant was born full term via primary cesarean section to a 26-yearold Gravida 1 Para 0 (GIPO) mother at a local hospital. Pre-natal history was unremarkable. At 19 days of life, the patient was observed to have a gradually enlarging firm mass at the left maxillary area. No other symptoms noted. At two months of life, the mass was excised. Gross examination revealed an irregularly shaped tissue measuring $3.8 \times 3 \times 2 \mathrm{~cm}$ with a gray to black, fleshy and gritty cut surface. Microscopically, the tumor is composed of nests of neoplastic cells, some containing pigment, arranged in an alveolar pattern separated by fibrovascular stroma (Figure 1). The tumor cell population is biphasic. It is composed of small, round, neuroblast-like cells with dark nuclei and scanty cytoplasm and flattened to cuboidal epithelioid cells containing melanin-like cytoplasmic pigment (Figure 2). These histomorphologic features are consistent with MNETI. Differential diagnoses considered were Non-Hodgkin Lymphoma, Malignant Melanoma, Rhabdomyosarcoma and Ewing Sarcoma. However, the biphasic morphology was deemed sufficiently distinct as to rule out these diagnoses on morphologic grounds. A few weeks later, recurrence and rapid growth of the mass were noted. The patient was then referred to the Pediatric-Oncology Section. To confirm the previously issued diagnosis, HMB45 (Figure 3), Neuron Specific Enolase (Figure 4) and Cytokeratin (Figure 5) immunohistochemistry were performed, which were all positive in the pigmented epithelioid cells. The Synaptophysin showed positivity in the small, neuroblast-like cells (Figure 6). CT Scan of the head was requested which revealed an expansile hyperdense lytic lesion of the left maxilla which extended to the midline and the left cheek (Figure 7). Since the mass was unresectable, the patient underwent six cycles of chemotherapy (Cyclophosphamide, Vincristine and Doxorubicin). The patient tolerated the procedure and the mass decreased in size 


\section{UNDER THE MICROSCOPE}

Philippine Journal Of Otolaryngology-Head And Neck Surgery

Vol. 26 No. 1 JANUARY - JUNE 2011

by 30 to $40 \%$. One month after treatment, excision of the mass was done showing a $4.5 \times 4 \times 3.5 \mathrm{~cm}$, hard mass with brown black, solid, gritty cut surface (Figure 8). Microscopic sections of the resected mass showed post-chemotherapy related changes consisting of predominantly melanin-containing epithelioid cells and reduced or disappearance of the neuroblast-like cells (Figure 9). Facial reconstruction was done. Three weeks after the surgery, there was no noted tumor recurrence.

\section{DISCUSSION}

MNETI (synonyms: retinal anlage tumor, progonoma) clinically presents as a rapidly growing, non-tender, solitary, expansile, partly pigmented mass, typically arising in the maxillary region. ${ }^{1,5}$ Radiographs often reveal a destructive, poorly demarcated radiolucency of the underlying bone with a faint "sunburst" appearance from mild calcification along vessels radiating from the center of the tumor. CT scans reveal a hyperdense mass. Microscopic sections usually show biphasic population of cells - small, neuroblast-like cells and larger melanin-containing epithelioid cells. Immunohistochemistry studies are helpful in differentiating MNETI from other "small round cell" tumors common in the head and neck region. In this case, the melanocytic cells are immunoreactive to HMB45, NSE and Cytokeratin while the neuroblast-like cells are immunoreactive to Synaptophysin, confirming the diagnosis of MNETI.' The treatment of choice is complete surgical resection. Patients with MNETI that are not amenable to surgical management alone may receive other modes of treatment. Chemotherapy may serve as an alternative or adjuvant option in the treatment of widely extensive MNETI.' The prognosis is still controversial. Many authors consider it good but there are only a few

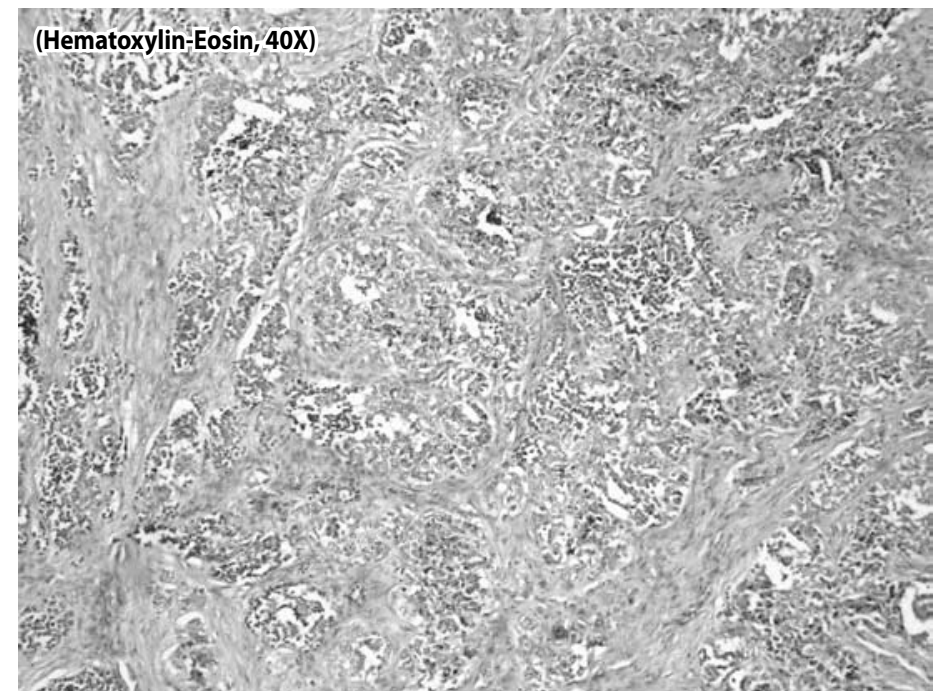

Figure 1. Neoplastic cells, some containing pigment, arranged in an alveolar pattern separated by fibrovascular stroma (H\&E, 40X) cases in the literature. Some authors have demonstrated a significant reduction of the neuroblastic-like component with chemotherapy with predominance of melanin-containing epithelioidcells. ${ }^{6}$ When metastasis develops (up to 7\% of cases) it is the "neuroblast-like" component that is regarded as the aggressive part of the neoplasm.

Although MNETI is reported to have a good prognosis, recurrences can occur especially within the first six months, hence, the need for close follow-up post-operatively. Close follow-up and early resection of local recurrences minimize complications and thereby avoid loss of local function. ${ }^{4}$ The rarity of this tumor demands reporting in order to elucidate the real nature of the lesion, as well as its natural outcome.

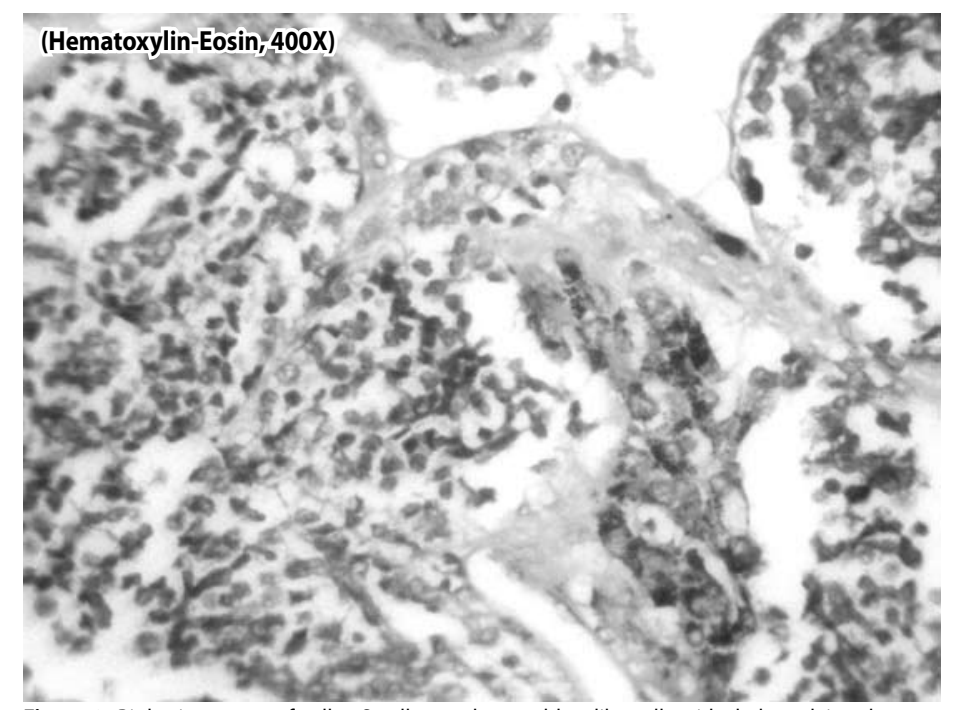

Figure 2. Biphasic pattern of cells: Small, round, neuroblast-like cells with dark nuclei and scanty cytoplasm and flattened to cuboidal epithelioid cells containing melanin-like cytoplasmic pigment $(H \& E, 400 X)$

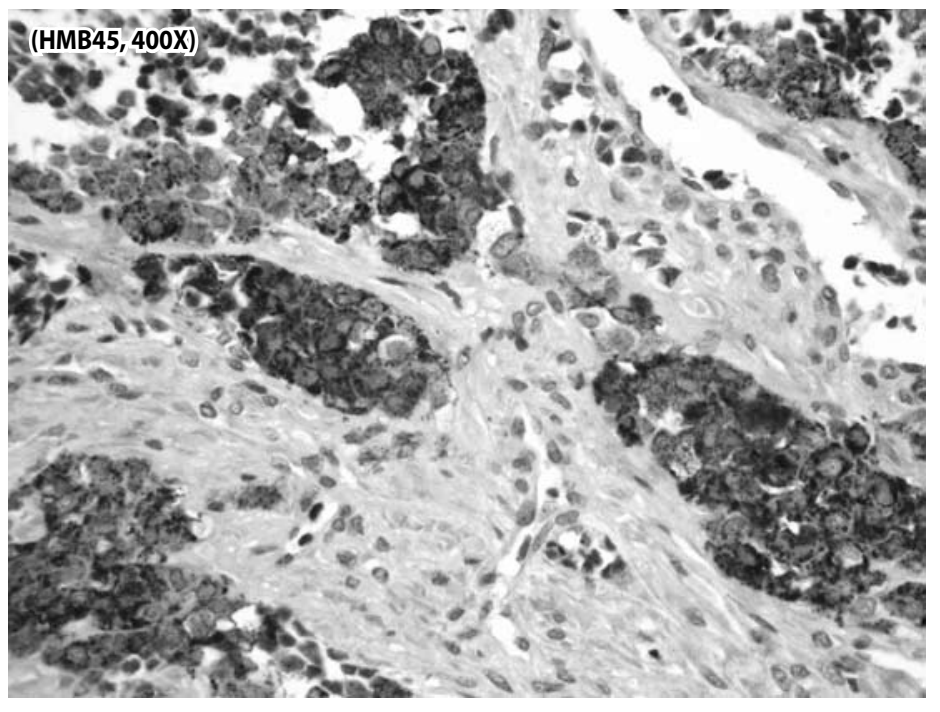

Figure 3. Melanin-like containing epithelioid tumor cells immunoreactive for HMB45 (400X) 


\section{UNDER THE MICROSCOPE}

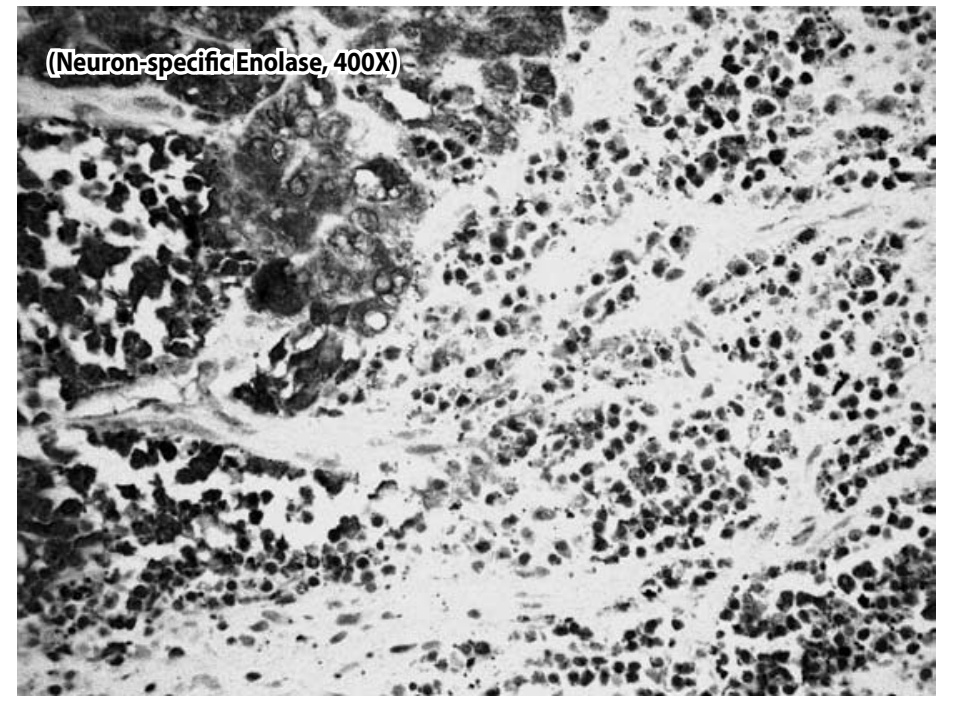

Figure 4. Melanin-like containing epithelioid tumor cells immunoreactive for Neuron-specific Enolase (400X)

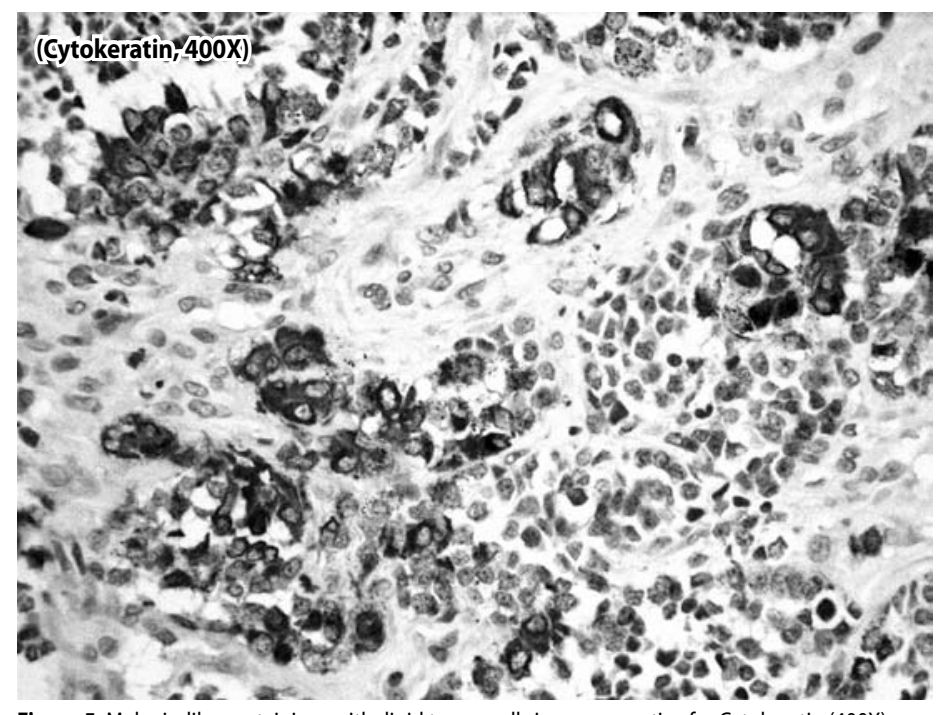

Figure 5. Melanin-like containing epithelioid tumor cells immunoreactive for Cytokeratin (400X)

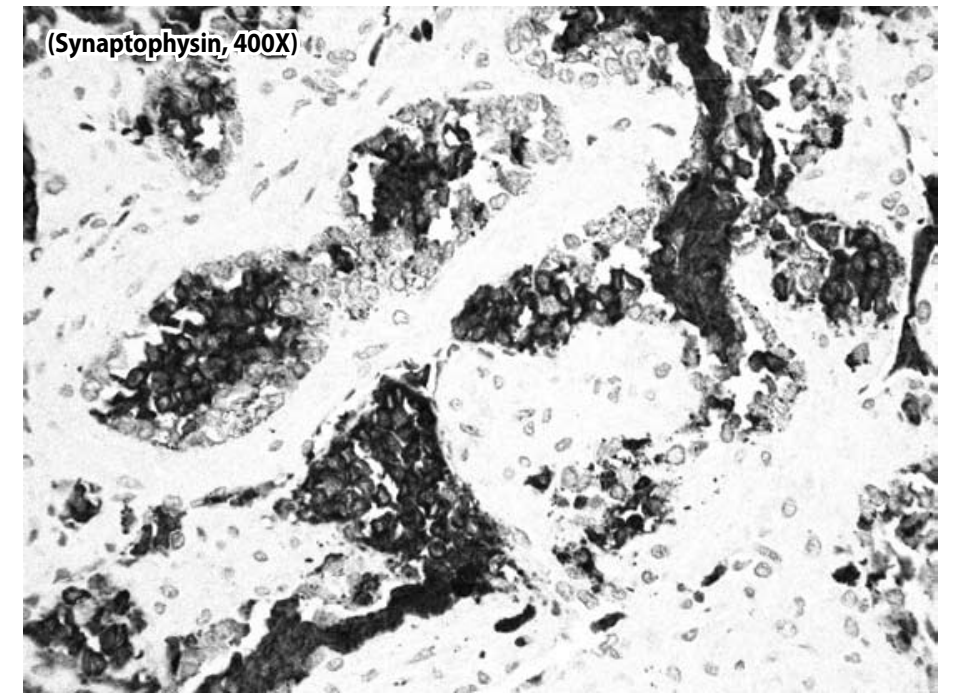

Figure 6. Small, neuroblast-like cells immunoreactive for synaptophysin (400X)

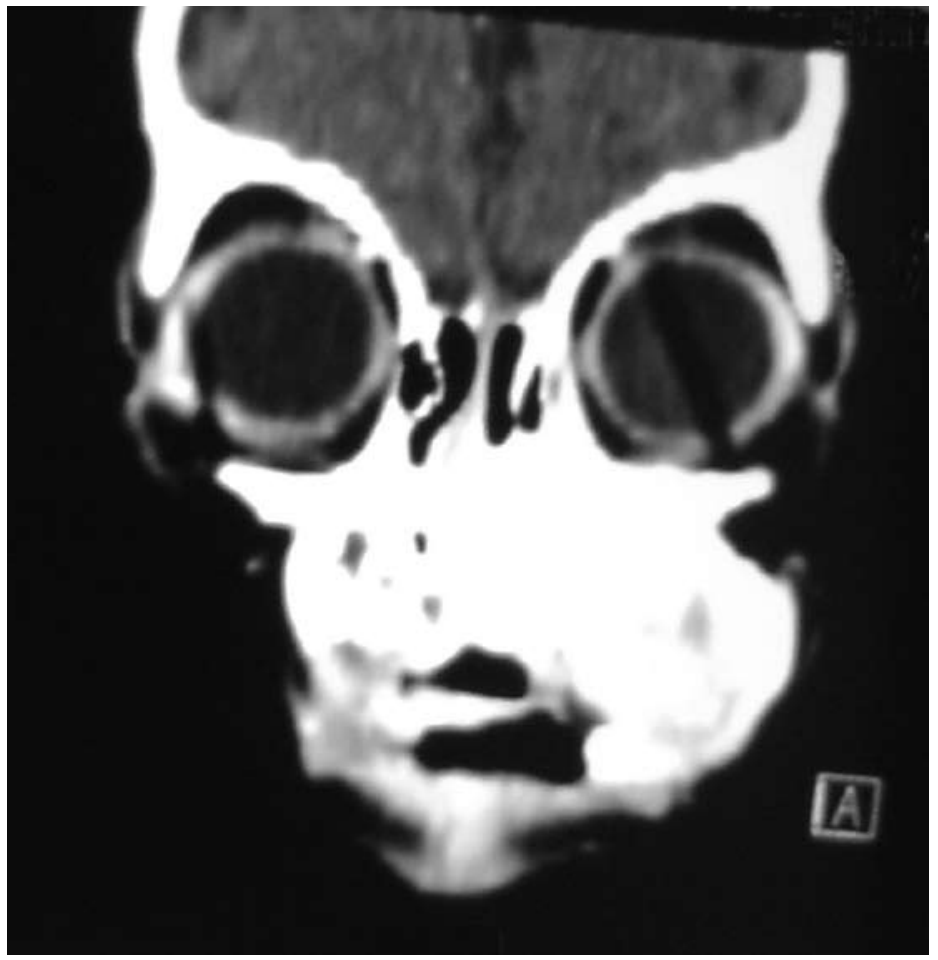

Figure 7. CT-scan of the head with contrast showing an expansile hyperdense lytic lesion of the left maxilla which extended to the midline and the left cheek 


\section{UNDER THE MICROSCOPE}

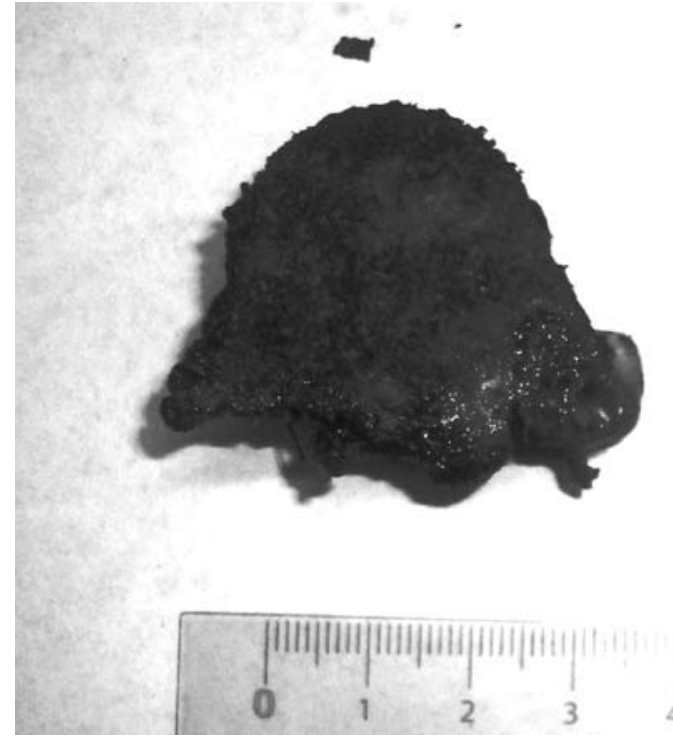

Figure 8. Post-chemotherapy excision of the gross specimen

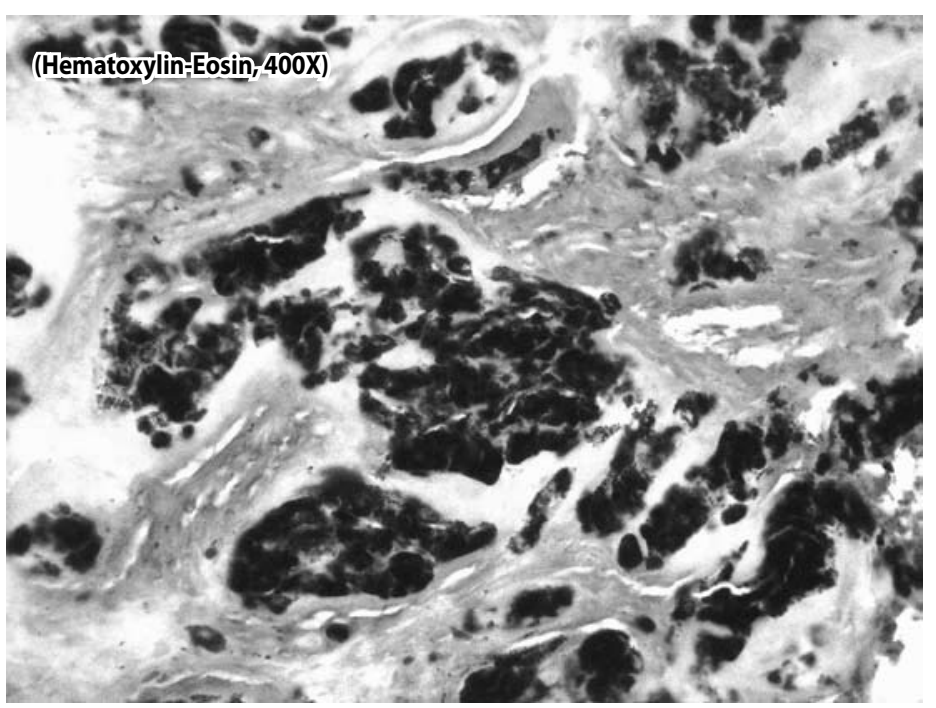

Figure 9. Post-chemotherapy related changes consisting of predominantly melanin-containing epithelioid cells and disappearance of neuroblast-like cells (H \& E, 400X)

\section{REFERENCES}

1. Agarwal P, Saxena S, Kumar S, Gupta R. Melanotic Neuroectodermal Tumor of Infancy: Presentation of a Case Affecting the Maxilla. J Oral Maxillofacial Pathol. 2010 Jan - June; 14(1): $29-32$

2. Retna Kumari N, Sreedharan S., Balachandran D., Melanotic Neuroectodermal Tumor of Infancy: A Case Report. Journal Indian Society of Pedodontics Preventive Dentistry. 2007 Sept; 25(3):148 $-151$.

3. Pontejos A, Lopez J, Jurado A. Melanotic Neuroectodermal Tumor of Infancy: A Case Report Philipp J Otolaryngol Head \& Neck Surgery. 1983: 192 - 194

4. Costa de Arau'jo PP, Tincani AF, Paiva VP, Loureiro Neta IS, Cardinalle d IA, de Cassia Pereira d R, Brandalise SR. Melanotic neuroectodermal tumor of infancy (Progonoma)-CClinical, radiological, pathological features and literature review. Int J Ped Otorhinolaryngol Extra. 2007 June;2(2):111-115.

5. Mosby EL, Lowe MW, Cobb CM, Ennis RL. Melanotic neuroectodermal tumor of infancy: review of the literature and report of a case. J Oral Maxillofacial Surg. 1992;50:886-894.

6. Mello RJ, Vidal AK, Fittipaldi HM Jr, Montenegro LT, Calheiros LM, Rocha GI. Melanotic neuroectodermal tumor of infancy: Clinicopathologic study of a case, with emphasis on the chemotherapeutic effects. Int J Surg Pathol 2000 Jul;8(3):247-251 